\title{
Effect of FTY720-phosphate on the expression of inflammation-associated molecules in astrocytes in vitro
}

\author{
STEFANIE JANSSEN ${ }^{1,2}$, CAROLINE SCHLEGEL ${ }^{1}$, VIKTORIA GUDI ${ }^{1}$, CHITTAPPEN KANDIYIL PRAJEETH $^{1}$, \\ THOMAS SKRIPULETZ ${ }^{1}$, CORINNA TREBST ${ }^{1}$ and MARTIN STANGEL ${ }^{1,2}$ \\ ${ }^{1}$ Clinical Neuroimmunology and Neurochemistry, Department of Neurology, Hannover Medical School, \\ Hannover D-30625; ${ }^{2}$ Center for Systems Neuroscience, Hannover D-30559, Germany
}

Received September 9, 2014; Accepted May 21, 2015

DOI: $10.3892 / \mathrm{mmr} .2015 .4120$

\begin{abstract}
FTY720 is a new oral immunomodulatory therapy for the treatment of multiple sclerosis (MS). There is strong evidence that FTY720 has direct effects on brain resident cells such as astrocytes acting via sphingosine-1-phosphate (S1P) receptors. In the present study, the mRNA expression of $\mathrm{S} 1 \mathrm{P}$ receptors as well as selected cytokines, chemokines and growth factors were investigated in primary murine astrocytes under inflammatory conditions in the presence or absence of the phosphorylated form of FTY720 (FTY720-P). Following stimulation with either the pro-inflammatory cytokine tumor necrosis factor- $\alpha$ (TNF- $\alpha$ ) or with bacterial lipopolysaccharide, there was an increased expression of the receptors S1P1 and S1P3, the cytokines and chemokines interleukin (IL)-1 $\beta$, chemokine (C-C-motif) ligand 2 (CCL-2), CCL-20 and chemokine (C-X-C-motif) ligand 12 as well as the growth factors insulin-like growth factor-1, ciliary neurotrophic factor and glial cell line-derived neurotrophic factor (GDNF). FTY720-P led to an increased expression of IL-1 $\beta$ and GDNF at distinct time points following co-stimulation with TNF- $\alpha$ compared with TNF- $\alpha$ treatment alone. However, the presence of FTY720-P did not have any further significant effects on the expression of S1P receptors, cytokines or growth factors, suggesting that the regulation of these target genes in astrocytes is not likely to be a major mechanism underlying the effect of FTY720-P in diseases such as MS.
\end{abstract}

\section{Introduction}

Multiple sclerosis (MS) is a demyelinating autoimmune disease of the central nervous system (CNS) in which the

Correspondence to: Professor Martin Stangel, Clinical Neuroimmunology and Neurochemistry, Department of Neurology, Hannover Medical School, Carl-Neuberg-Straße 1, Hannover D-30625, Germany

E-mail: stangel.martin@mh-hannover.de

Key words: FTY720, fingolimod, astrocytes, inflammation, multiple sclerosis natural repair process, remyelination, is often incomplete $(1,2)$. Current treatments for MS predominantly modulate immunological pathways to suppress inflammatory outbreaks. However, regenerative therapies are not available.

FTY720, 2-a mino-2-[2-(4-octylphenyl)ethyl] propane-1,3-diol, clinically known as fingolimod (Gilenya ${ }^{\circledR}$ ), is an approved oral immunomodulatory therapy in relapsing-remitting MS $(3,4)$. The mechanism of action is proposed to mainly affect lymphocyte migration. Binding of FTY720-phosphate (FTY720-P) to sphingosine-1-phosphate receptor 1 (S1P1) on lymphocytes causes internalization and degradation of the surface receptor (5). Due to this functional antagonism, infiltration of the CNS is prevented since lymphocytes cannot respond to S1P gradients and do not egress from lymphoid tissue $(6,7)$.

As S1P1, 2, 3 and 5 were found to be expressed on brain resident cells (8-10) and the lipophilic pre-drug FTY720 easily crosses the blood brain barrier (11), it is suggested that FTY720 may also have direct effects within the CNS. Choi et al demonstrated that FTY720 exerts its functions in experimental autoimmune encephalomyelitis (EAE) via action on S1P1 receptors in astrocytes (12). In vitro, FTY720-P increases the migration of astrocytes and is involved in the phosphorylation of extracellular signal-regulated kinase, $\mathrm{Ca}^{2+}$ signaling, as well as mediation of phospholipase $\mathrm{C}$ and adenylyl cyclase $(13,14)$.

In the present study, the effects of FTY720-P on S1P receptors as well as the expression of cytokines, chemokines and growth factors was analyzed in primary murine astrocytes under inflammatory conditions.

\section{Materials and methods}

Preparation and culture of astrocytes. Astrocytes were prepared from newborn C57BL/6 mouse brains as previously described (15). C57BL/6 mice were housed under specific pathogen-free conditions in the central animal facility (ZTL), Hannover Medical School (Hannover, Germany). All animal care procedures were performed according to international guidelines on the use of laboratory animals (16). The experimental procedures were performed according to the German Animal Welfare Act and approved by the Local Institutional Animal Care and Research Advisory Committee of the Hannover Medical School and the Lower Saxony State 
Office for Consumer Protection and Food Safety (approval ID nos. §4-2012/09 and §4-2014/74). Neonatal mice (1-3 days old) were sacrificed by decapitation and brains were collected. Following removal of the olfactory bulbs and cerebellum, brains were freed from meninges and dissociated mechanically and enzymatically ( $0.1 \%$ trypsin). Cells from two brains were plated on poly-L-lysine (Sigma-Aldrich, St. Louis, MO, USA) coated tissue flasks $\left(75 \mathrm{~cm}^{2}\right.$; Sarstedt, Nümbrecht, Germany) containing Dulbecco's modified Eagle's medium (DMEM; Invitrogen Life Technologies, Karlsruhe, Germany) supplemented with $10 \%$ fetal calf serum (FCS) and $1 \%$ penicillin/streptomycin (medium referred to as $\mathrm{MGP}^{+}$). $\mathrm{MGP}^{+}$was changed after $24 \mathrm{~h}$ and on day 4 and 8 . Following removal of loosely attached microglia on day 9 or 10 (shaking for 1-2 h in an orbital shaker) and oligodendrocyte precursor cells at day 10 or 11 (shaking overnight in an orbital shaker), the remaining astrocytes were treated with antimitotic arabinosylcytosine (Ara-C; $100 \mu \mathrm{M}$, Sigma-Aldrich) to avoid the growth of new oligodendrocytes and microglia. Medium containing Ara-C was then removed after 72 h, cells were washed with phosphate-buffered saline and harvested with $0.25 \%$ trypsin/0.05\% EDTA (PAA Laboratories GmbH, Coelbe, Germany). Astrocytes were plated at the indicated cell densities for each experiment. These cultures yielded a purity of $\sim 99 \%$ as judged by glial fibrillary acidic protein (GFAP) immunostaining.

Tumor necrosis factor (TNF)- $\alpha$, lipopolysaccharide (LPS) and FTY720-P stimulation. For all experiments, the phosphorylated form of FTY720 (Cayman Chemicals, Ann Arbor, MI, USA) was reconstituted in $50 \mathrm{mM}$ dimethyl sulfoxide hydrochloric acid (Sigma-Aldrich), aliquoted and stored at $-20^{\circ} \mathrm{C}$. The final FTY720-P concentration for treatment of astrocytes was $1 \mu \mathrm{M}$. This was based on previous studies in vitro (14) and in EAE rats (11). In our experiments, FTY720-P was also assessed at concentrations of 0.01 and $0.1 \mu \mathrm{M}$ (data not shown). However, the strongest effect on gene expression was found with $1 \mu \mathrm{M}$ FTY720-P.

To simulate inflammatory conditions, recombinant murine TNF- $\alpha$ (20 ng/ml; PeproTech, Inc., Rocky Hill, NJ, USA) and bacterial LPS (100 ng/ml, from Escherichia coli 0111:B4; Sigma-Aldrich) were used. For the stimulations as well as co-stimulations, all reagents were diluted in DMEM (Invitrogen Life Technologies) supplemented with $10 \%$ FCS (Merck Millipore, Darmstadt, Germany) and 1\% penicillin/streptomycin to the final concentrations.

Proliferation assay. To determine the number of astrocytes undergoing cell division during $24 \mathrm{~h}$ of incubation, $1 \times 10^{4}$ cells were seeded on uncoated $12 \mathrm{~mm}$ glass cover slips (Thermo Fisher Scientific, Inc., Waltham, MA, USA). After 24 h, astrocytes were treated with $\mathrm{MGP}^{+} \pm 1 \mu \mathrm{M}$ FTY720-P and incubated for $24 \mathrm{~h}$. Dividing nuclei were then labeled with the monoclonal mouse anti-human KI-67 antibody (1:300; cat. no. 550609; BD Biosciences, San Jose, CA, USA) and 4',6-diamidino-2-phenylindole (DAPI; Invitrogen Life Technologies, Carlsbad, CA, USA) in a final concentration of 1:1,000. Polyclonal rabbit anti-GFAP (1:300; cat. no. Z 0334; Dako Denmark A/S, Glostrup, Denmark) antibody was used as a marker for astrocytes. For quantification, the cover slips
Table I. Primers used for quantitative polymerase chain reaction.

\begin{tabular}{ll} 
Gene & Gene expression assay number \\
\hline S1P1 & mm00514644_m1 \\
S1P3 & mm04229896_m1 \\
S1P5 & mm01177724_m1 \\
IL-1 $\beta$ & mm01336189_m1 \\
CCL-2 & mm00441242_m1 \\
CCL-20 & mm01268754_m \\
CXCL-12 & mm00445553_m1 \\
IGF-1 & mm00439560_m1 \\
CNTF & mm 00446373_m1 \\
GDNF & mm00599849_m1 \\
HPRT & mm00446968_m1
\end{tabular}

S1P, sphingosine-1-phosphate receptor; IL, interleukin; CCL-2, chemokine (C-C motif) ligand 2; CCL-20, chemokine (C-C motif) ligand 20; CXCL-12, chemokine (C-X-C motif) ligand 12; IGF, insulin-like growth factor; CNTF, ciliary neurotrophic factor; GDNF, glial cell line-derived neurotrophic factor; HPRT, hypoxanthine-guanine phosphoribosyltransferase.

were divided into six optic fields and three images per field were analyzed in a blinded manner using an Olympus BX61 microscope (Olympus, Tokyo, Japan). GFAP/KI-67 positive cells were counted and set in relation to the total astrocyte number. Only cells with DAPI-labeled nuclei were included in the analysis.

Isolation of RNA and reverse transcription quantitative polymerase chain reaction ( $R T-q P C R)$. For mRNA measurements, $3 \times 10^{5}$ astrocytes were plated per well in 6-well plates (Nalgene Nunc, Rochester, NY, USA) in $\mathrm{MGP}^{+}$. The medium was changed after $24 \mathrm{~h}$. After 5 days of incubation, cells were treated for 3, 6, 12 or $24 \mathrm{~h}$ with $100 \mathrm{ng} / \mathrm{ml}$ LPS \pm FTY720-P $(1 \mu \mathrm{M})$ or $20 \mathrm{ng} / \mathrm{ml}$ TNF- $\alpha \pm$ FTY720-P or FTY720-P alone. Total RNA was isolated using the RNeasy Mini kit (Qiagen, Valencia, CA, USA) according to the manufacturer's instructions and the RNA concentration was measured with the BioPhotometer plus (Eppendorf, Hamburg, Germany). cDNA was synthesized using the High Capacity cDNA Reverse Transcription kit (Applied Biosystems, Foster City, CA, USA). qPCR analysis was performed using the StepOne ${ }^{\mathrm{TM}}$ Real Time PCR System (Invitrogen Life Technologies) and appropriate TaqMan assays (Applied Biosystems; see Table I). A negative control containing PCR amplification mix without the reverse transcribed cDNA template was included for each PCR plate. The $\Delta \Delta \mathrm{Ct}$ method was used to determine differences in the expression between untreated and stimulated cells. The gene expression of S1P1, S1P3, S1P5, interleukin-1 $\beta$ (IL-1 $\beta$ ), chemokine (C-C motif) ligand 2 (CCL-2), CCL-20, chemokine (C-X-C motif) ligand 12 (CXCL-12), insulin-like growth factor (IGF)-1, ciliary neurotrophic factor (CNTF) and glial cell line-derived neurotrophic factor (GDNF) was quantified against the housekeeping gene hypoxanthine-guanine phosphoribosyl transferase. 
A

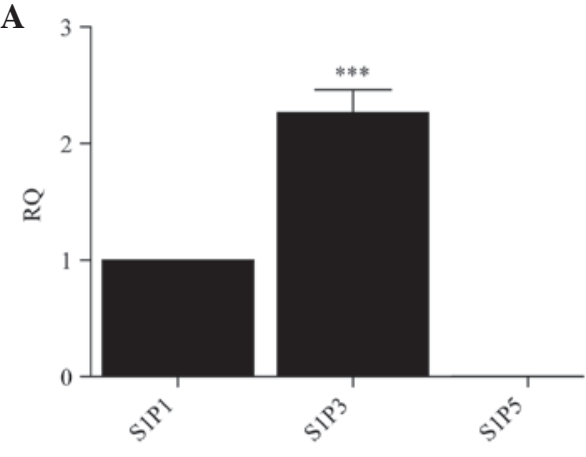

B

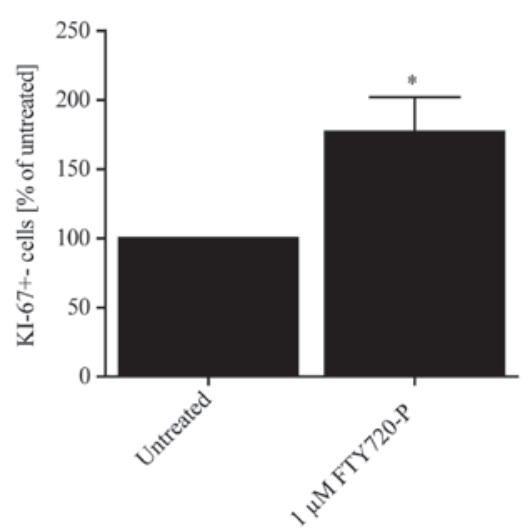

Figure 1. Expression of S1P receptors is S1P3>S1P1 >S1P5 in untreated murine astrocytes and proliferation is induced following treatment with FTY720-P. (A) Quantitative polymerase chain reaction was used to quantify the expression levels of S1P1, S1P3 and S1P5 in untreated cultured astrocytes. Compared with $\mathrm{S} 1 \mathrm{P} 1$, the mRNA expression of S1P3 was significantly higher $\left({ }^{* * *} \mathrm{P}<0.001\right)$. mRNA for S1P5 was detected only at an extremely low level compared with S1P1. Data from four independent experiments are presented as the mean \pm SEM. (B) Biological activity of FTY720-P was evaluated by measuring the proliferation of astrocytes via KI-67 immunocytochemistry. Treatment of astrocytes with $1 \mu \mathrm{M}$ FTY720-P for $24 \mathrm{~h}$ significantly induced proliferation ("P<0.05, compared with the untreated cells). Data from four independent experiments are presented as the mean \pm SEM. SIP, sphingosine-1-phosphate; SEM, standard error of the mean; RQ, relative quantity; FTY720-P, FTY720-phosphate.

Statistical analysis. All data were plotted using GraphPad Prism version 5.02 (GraphPad Software, Inc., San Diego CA, USA). One-way analysis of variance was used for statistical analysis followed by Fisher's test for post hoc comparison. Values are presented as the arithmetic mean \pm standard error of the mean. $\mathrm{P}<0.05$ was considered to indicate a statistically significant difference.

\section{Results}

$S 1 P$ receptors are expressed on astrocytes and treatment with FTY720-P augments astrocytic proliferation. Initially, the level of mRNA of each $\mathrm{S} 1 \mathrm{P}$ receptor (S1P1, 3 and 5) on primary mouse astrocytes was evaluated under basal conditions using qPCR. The expression levels in primary murine astrocytes followed a pattern of S1P3 $>$ S1P1 $>$ S1P5 in untreated cells (Fig. 1A). Due to the fact that the mRNA levels of S1P5 were hardly detectable, this receptor subtype was omitted from further experiments.

Based on previous studies $(14,17,18)$ the effect of $24 \mathrm{~h}$ treatment with FTY720-P on the proliferation of cultured astrocytes compared with untreated control cells was analyzed. Fig. 1B illustrates that FTY720-P increased the proliferation rate of primary astrocytes as measured by KI-67 immunostaining.

S1P receptor expression is increased under pro-inflammatory conditions and is not affected by FTY720-P. Inflammatory conditions were induced by stimulating astrocytes with either LPS or the pro-inflammatory cytokine TNF- $\alpha$ in the presence or absence of FTY720-P. After 3, 6, 12 and 24 h, the mRNA levels of S1P1 and S1P3 were measured.

As shown in Fig. 2, the mRNA levels of S1P1 and S1P3 increased significantly following treatment with TNF- $\alpha$ or LPS compared with the untreated control cells. In comparison with TNF- $\alpha$ or LPS treatment alone, no significant differences in the expression of S1P1 or S1P3 were observed following co-stimulation with LPS and FTY720-P or TNF- $\alpha$ and FTY720-P (Fig. 2).
Expression of cytokines and chemokines under pro-inflammatory conditions and FTY720-P. Treatment with TNF- $\alpha$ or LPS induced an increase in the expression of IL-1 $\beta$ (Fig. 3A and B), CCL-2 (Fig. 3C and D) and CXCL-12 (Fig. 4C and D). Expression of CCL-20 was significantly increased after 3 h treatment with TNF- $\alpha$ and subsequently decreased, whereas following treatment with LPS an increased expression was only observed after $24 \mathrm{~h}$ treatment (Fig. 4A and B).

Previous studies have suggested that FTY720-P mediates effects on the inflammation-induced expression and secretion of different types of cytokines and chemokines (19-21). In the present study, treatment with FTY720-P did not affect the inflammation-induced expression of CCL-2, CCL-20 or CXCL-12 (Figs. 3C, D and 4A-D). TNF- $\alpha$-induced upregulation of IL-1 $\beta$ was significantly augmented in the presence of FTY720-P only after $12 \mathrm{~h}$ (Fig. 3A). This effect was not observed after 3, 6 or 24 h or following stimulation with LPS and FTY720-P (Fig. 3B).

Expression of growth factors under pro-inflammatory conditions and treatment with FTY720-P. The effect of TNF- $\alpha$ and LPS stimulation on the expression of several growth factors was further evaluated.

The expression of IGF-1 was, similar to CNTF, partially elevated following LPS treatment, whereas TNF- $\alpha$ evoked a more prominent induction of gene expression (Fig. 5A-D). In comparison with TNF- $\alpha$ or LPS treatment alone, FTY720-P did not induce any significant alterations in the gene expression of IGF-1 or CNTF (Fig. 5A-D).

GDNF gene expression has been demonstrated to be induced via S1P receptor signaling in astrocytes (22). As illustrated in Fig. 5E and F, it was found that TNF- $\alpha$ and LPS induced a significant increase in GDNF mRNA levels after $6 \mathrm{~h}(\mathrm{TNF}-\alpha)$ and after 12 and $24 \mathrm{~h}$ (LPS). However, TNF- $\alpha$-induced gene expression decreased with time and mRNA levels returned to basal levels at $24 \mathrm{~h}$. Following stimulation with TNF- $\alpha$ and FTY720-P the mRNA level was significantly higher after $24 \mathrm{~h}$ as compared with treatment with TNF- $\alpha$ alone (Fig. 5E). 
A

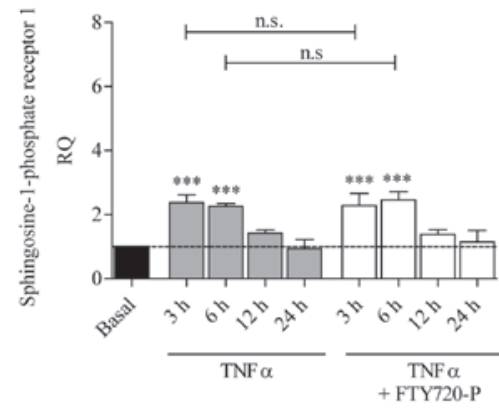

C

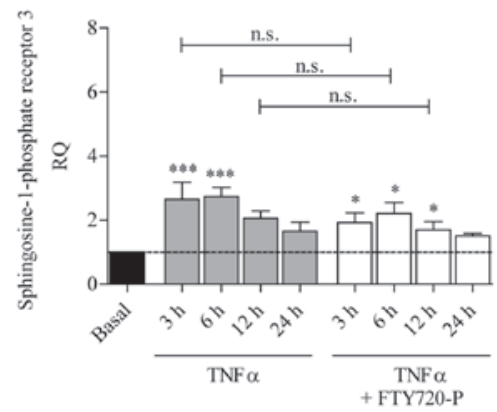

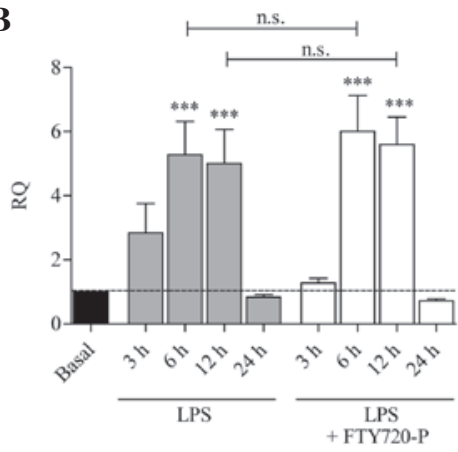

D

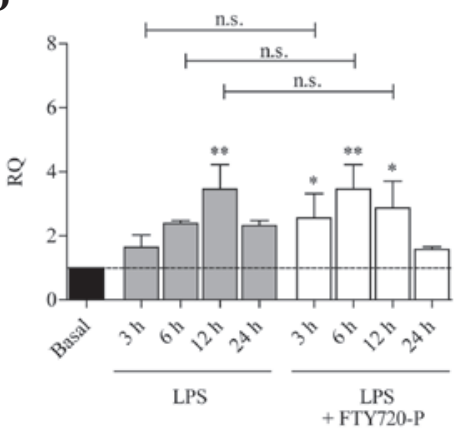

Figure 2. S1P receptor expression is induced upon stimulation with TNF- $\alpha$ and LPS in cultured murine astrocytes and is not affected by FTY720-P. The columns represent the RQ of gene expression following stimulation with (A and C) TNF- $\alpha$ (grey columns) or (B and D) LPS (grey columns), or following co-stimulation with TNF- $\alpha /$ LPS and FTY720-P (white columns) for 3, 6, 12 or $24 \mathrm{~h}$. The dashed line represents the basal expression level in untreated astrocytes. Upon activation with TNF- $\alpha$ or LPS, mRNA levels of (A and B) S1P1 and (C and D) S1P3 were upregulated compared with untreated astrocytes (grey columns); this effect was not altered in the presence of FTY720-P (white columns). Data from between three and five experiments are presented as the mean \pm standard error of the mean. ${ }^{*} \mathrm{P}<0.05,{ }^{* *} \mathrm{P}<0.005$ and ${ }^{* * * *} \mathrm{P}<0.001$, compared with the basal expression level (black column). n.s., not significant; SIP, sphingosine-1-phosphate; TNF- $\alpha$, tumor necrosis factor- $\alpha$; LPS, lipopolysaccharide; RQ, relative quantity; FTY720-P, FTY720-phosphate.

A

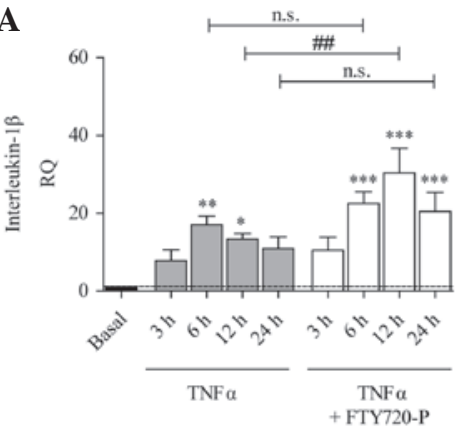

$\mathbf{C}$

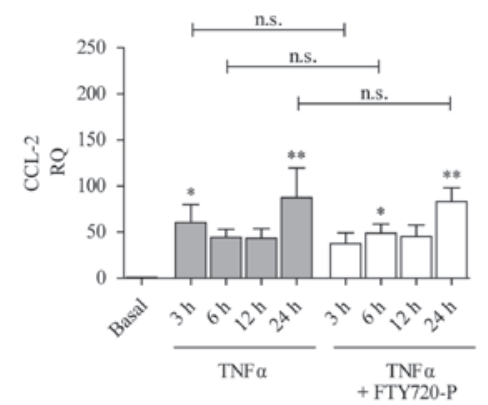

B

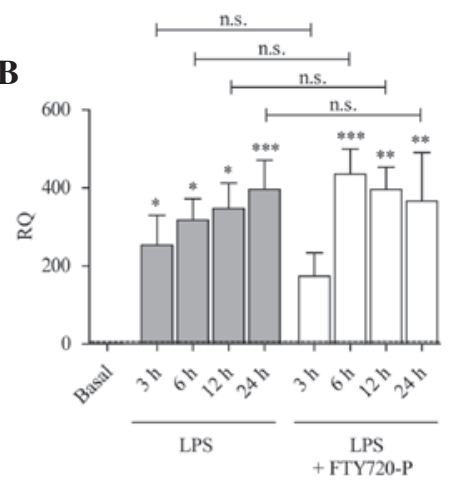

D

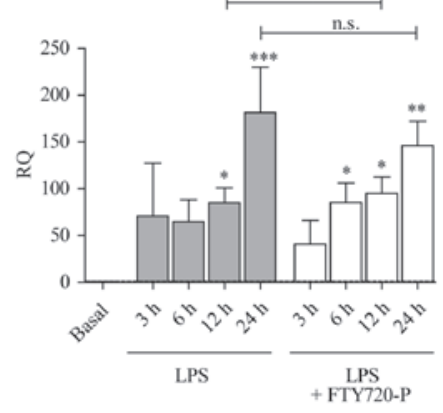

Figure 3. Expression of IL-1 $\beta$ and CCL-2 is increased under pro-inflammatory conditions and FTY720-P augments IL-1 $\beta$ expression after $12 \mathrm{~h}$ treatment. The columns represent the RQ of gene expression following stimulation with (A and C) TNF- $\alpha$ (grey columns) or (B and D) LPS (grey columns), or following co-stimulation with TNF- $\alpha$ /LPS and FTY720-P (white columns) for 3, 6, 12 or $24 \mathrm{~h}$. The dashed line represents the basal expression level in untreated astrocytes. TNF- $\alpha$ and LPS treatment induced the expression of (A and B) IL-1 $\beta$ and (C and D) CCL-2. The presence of FTY720-P did not alter the expression of (C and D) CCL-2, but potentiated TNF- $\alpha$-induced expression of (A) IL-1 $\beta$ (white columns) after $12 \mathrm{~h}$ treatment. Data from between three and five experiments are presented as the mean \pm standard error of the mean. ${ }^{*} \mathrm{P}<0.05,{ }^{* *} \mathrm{P}<0.005$ and ${ }^{* * *} \mathrm{P}<0.001$, compared with the basal expression level (black column); \#\#P<0.005, compared with TNF- $\alpha$ alone. n.s., not significant; IL, interleukin; CCL-2, chemokine (C-C-motif) ligand 2; RQ, relative quantity; TNF- $\alpha$, tumor necrosis factor- $\alpha$; LPS, lipopolysaccharide; FTY720-P, FTY720-phosphate. 


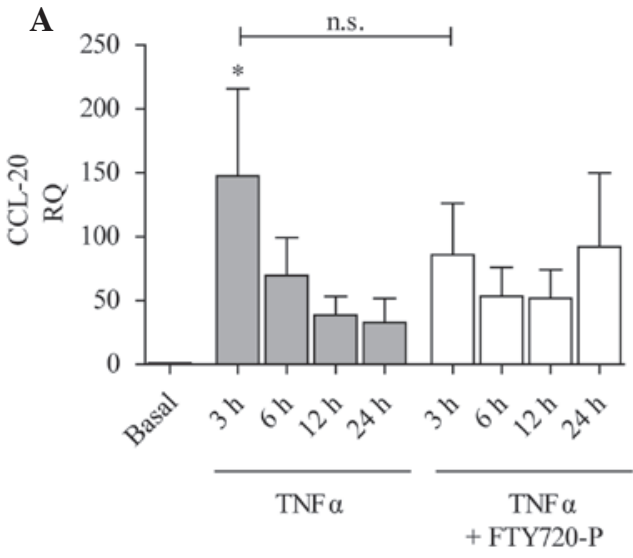

C

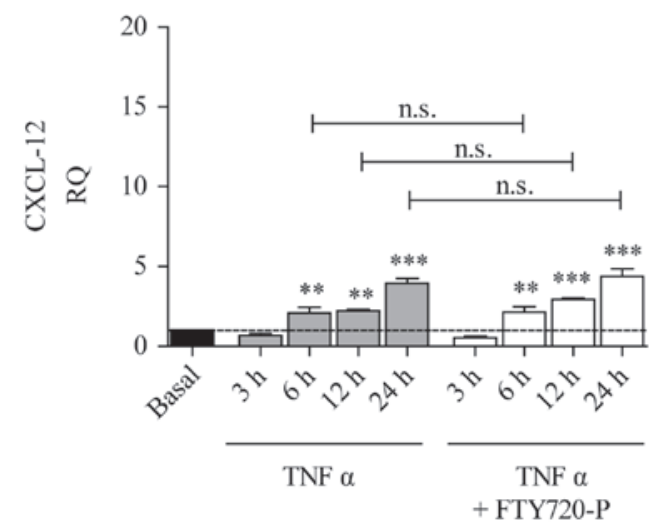

B

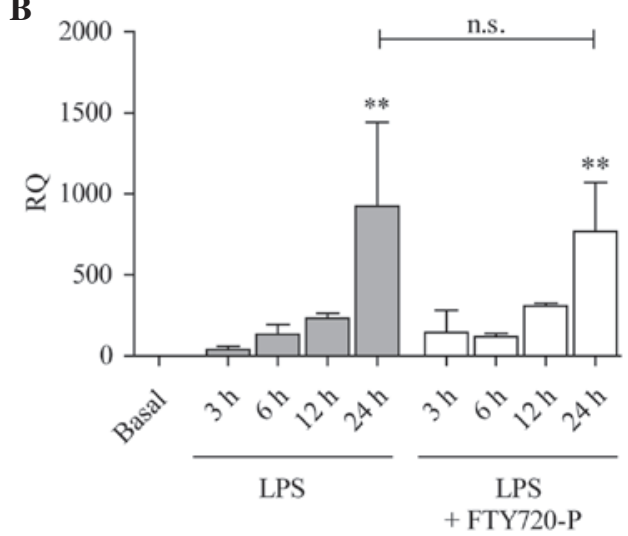

D

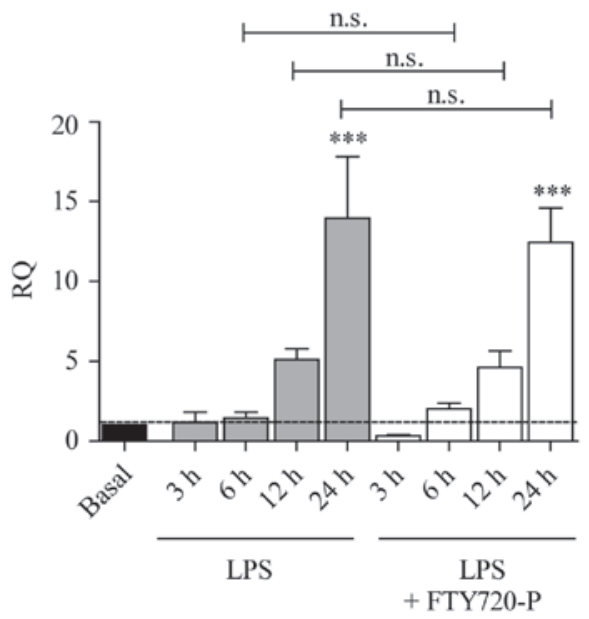

Figure 4. Expression of CCL-20 and CXCL-12 is increased under pro-inflammatory conditions and is not affected by FTY720-P. The columns represent the RQ of gene expression following stimulation with (A and C) TNF- $\alpha$ (grey columns) or (B and D) LPS (grey columns), or following co-stimulation with TNF- $\alpha$ /LPS and FTY720-P (white columns) for 3, 6, 12 or $24 \mathrm{~h}$. The dashed line represents the basal expression level in untreated astrocytes. Inflammatory stimulation by either TNF- $\alpha$ or LPS significantly induced the expression of (A and B) CCL-20 and (C and D) CXCL-12. Treatment with FTY720-P did not have any significant effects on the inflammation-induced expression of (A and B) CCL-20 (white columns) or (C and D) CXCL-12. Data from between three and five experiments are presented as the mean \pm standard error of the mean. ${ }^{*} \mathrm{P}<0.05,{ }^{* *} \mathrm{P}<0.005$ and ${ }^{* * * *} \mathrm{P}<0.001$, compared with the basal expression level (black). n.s., not significant; CCL-20, chemokine (C-C-motif) ligand 20; CXCL-12, chemokine (C-X-C-motif) ligand 12; RQ, relative quantity; LPS, lipopolysaccharide; TNF- $\alpha$, tumor necrosis factor- $\alpha$; FTY720-P, FTY720-phosphate.

However, this effect was not observed after 3,6 or $12 \mathrm{~h}$ treatment with TNF- $\alpha$, nor following treatment with LPS and FTY720-P (Fig. 5F).

\section{Discussion}

In the present study, qPCR was used to investigate the impact of FTY720-P on inflammation-induced mRNA levels of $\mathrm{S} 1 \mathrm{P}$ receptors as well as selected cytokines, chemokines and growth factors in primary murine astrocytes.

In our experiments, S1P1 and S1P3 mRNA was upregulated under inflammatory conditions and FTY720-P did not alter inflammation-induced increases in the receptors. Therefore, it was assumed that, although the two receptors are important in inflammation in astrocytes, FTY720-P is not involved in the transcriptional regulation of these receptors. Although no significant alterations in the expression of transforming growth factor- $1 \beta$ or platelet-derived neurotrophic factor $\alpha$ were detected following inflammatory stimuli ( \pm FTY720-P) in astrocytes (data not shown), the gene expression data demonstrated that TNF- $\alpha$ and LPS upregulated IL-1 $\beta$, CCL-2,
CCL-20, CXCL-12, IGF-1, CNTF and GDNF in cultured murine astrocytes. However, only small effects of FTY720-P treatment on the inflammation-induced expression of S1P receptors, cytokines and growth factors were observed.

Treatment with FTY720-P did not alter the TNF- $\alpha$ - or LPS-induced increased expression levels of CCL-2, CCL-20 and CXCL-12. Since Van Doorn et al (20) found a FTY720-mediated limitation of TNF- $\alpha$-induced CCL-2 release, it was hypothesized that the different results could be due to species differences or different FTY720-P concentrations. Based on studies by Foster et al (11), a relevant concentration was used that can be achieved in the brain in vivo.

Inflammation-induced IL-1 $\beta$ mRNA levels were augmented in the presence of FTY720-P in our experiments, although this effect was only statistically significant after $12 \mathrm{~h}$ of stimulation. Besides exacerbation of inflammation $(23,24)$, IL- $1 \beta$ is proposed to mediate regenerative functions, including support of oligodendrocyte survival and remyelination $(25,26)$. Thus, it is hypothesized that FTY720-P may increase the regenerative capacity of astrocytes at least during certain time points. 
A

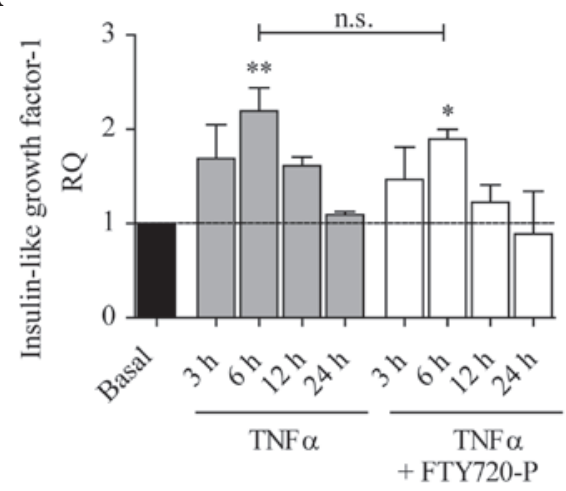

C

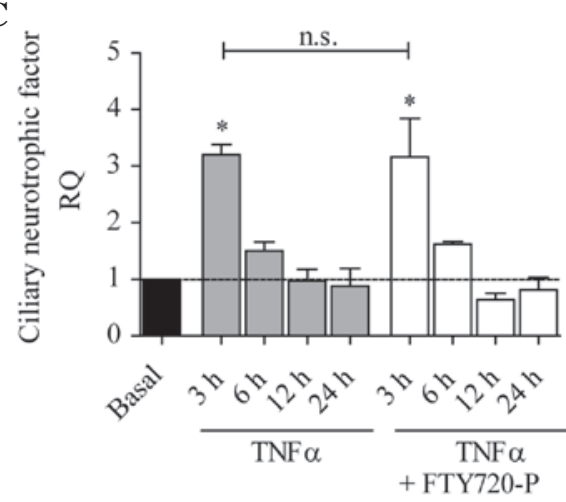

$\mathbf{E}$

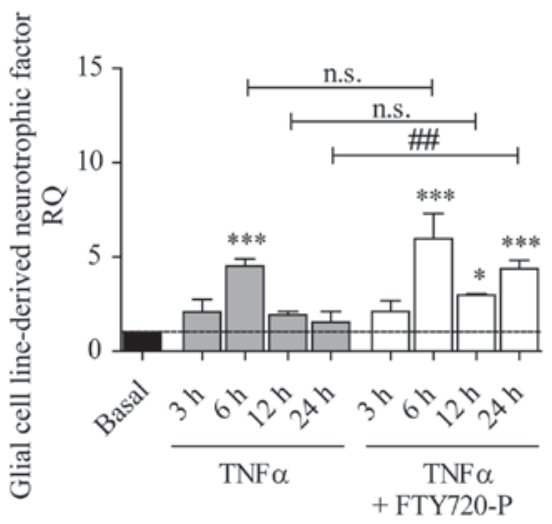

B

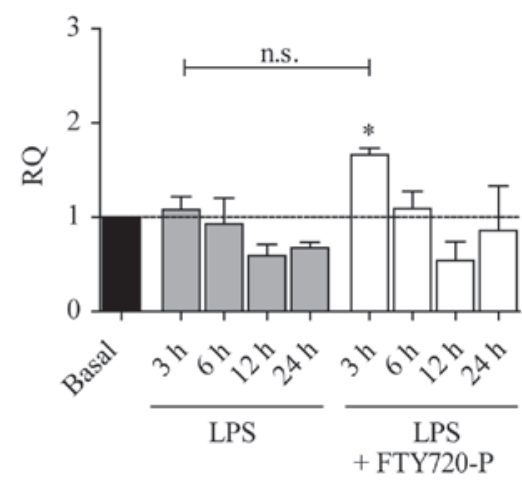

D

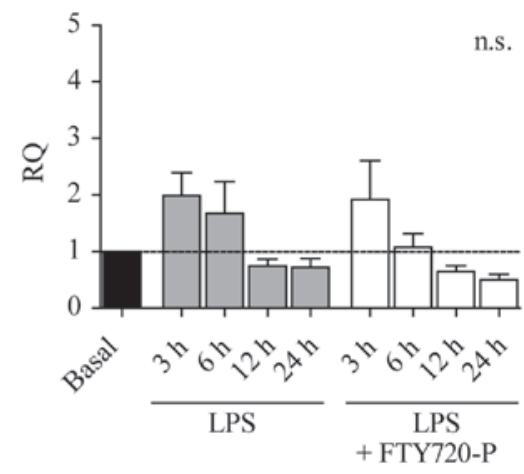

F

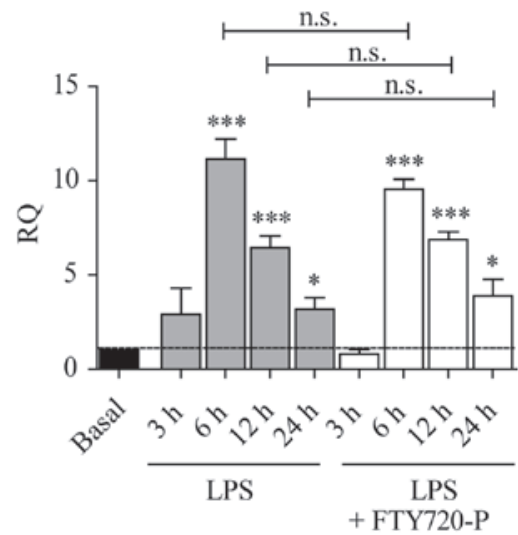

Figure 5. Expression of IGF-1, CNTF and GDNF is increased under pro-inflammatory conditions and GDNF expression is potentiated by FTY720-P after $24 \mathrm{~h}$ treatment. The columns represent the RQ of gene expression following stimulation with (A, C and E) TNF- $\alpha$ (grey columns) or (B, D and F) LPS (grey columns), or following co-stimulation with TNF- $\alpha$ /LPS and FTY720-P (white columns) for 3, 6, 12 or $24 \mathrm{~h}$. The dashed line represents the basal expression level in untreated astrocytes. (A) IGF-1 and (C) CNTF mRNA levels were increased upon TNF- $\alpha$ stimulation (grey columns), but not (B and D) LPS stimulation (grey columns). FTY720-P did not alter the expression of (A-D) IGF-1 or CNTF (white columns). Strong GDNF upregulation was induced by (E) TNF- $\alpha$ and (F) LPS (grey columns). (E) The presence of FTY720-P augmented TNF- $\alpha$-induced expression of GDNF after 24 h stimulation (white columns). Data from between three and five experiments are presented as the mean \pm standard error of the mean. ${ }^{*} \mathrm{P}<0.05,{ }^{* *} \mathrm{P}<0.005$ and ${ }^{* * *} \mathrm{P}<0.001$, compared with the basal expression level (black column); ${ }^{\#} \mathrm{P}<0.005$, compared with TNF- $\alpha$ alone n.s., not significant; GDNF, glial cell line-derived neurotrophic factor; IGF-1, insulin-like growth factor-1; CNTF, ciliary neurotrophic factor; TNF- $\alpha$, tumor necrosis factor- $\alpha$; LPS, lipopolysaccharide; RQ, relative quantity; FTY720-P, FTY720-phosphate.

GDNF was also upregulated under inflammatory conditions but FTY720-P did not have a major impact on these inflammation-induced alterations. However, after $24 \mathrm{~h}$ treatment with TNF- $\alpha$ and FTY720-P, the levels of GDNF were increased compared with TNF- $\alpha$ treatment alone. Accordingly, Yamagata et al demonstrated that S1P receptor modulation enhanced the mRNA and protein levels of GDNF within $24 \mathrm{~h}$ of incubation (22). As GDNF is a potent mediator of the survival of different types of neurons (27-29), the observed potentiation of GDNF expression could represent an FTY720-P-mediated neuroprotective effect in astrocytes during inflammatory processes.

In conclusion, the results suggest that FTY720-P is not likely to be involved in transcriptional modulation of S1P receptors, IL-1 $\beta$, CCL-2, CCL-20, CXCL-12, IGF-1, CNTF and GDNF in cultured murine astrocytes. To a certain extent, FTY720-P may be important in the potentiation of TNF- $\alpha$-induced GDNF and IL- $1 \beta$ gene expression, which possess regenerative capabilities and supports a protective environment following inflammation. 


\section{Acknowledgements}

The authors would like to thank Novartis for financial support and Mrs. I. Cierpka-Leja, Mrs. S. Lang and Mr. A. Niesel for their excellent technical assistance. This manuscript is part of a doctoral thesis at the University of Veterinary Medicine Hannover, which has been handed to the University (Stefanie Janßen, January 2014). Sections of this manuscript are included in a doctoral thesis at the Hannover Medical School (Caroline Schlegel, 2014).

\section{References}

1. Goldschmidt T, Antel J, König FB, Brück W and Kuhlmann T: Remyelination capacity of the MS brain decreases with disease chronicity. Neurology 72: 1914-1921, 2009.

2. Patrikios P, Stadelmann C, Kutzelnigg A, Rauschka H, Schmidbauer M, Laursen H, Sorensen PS, Brück W, Lucchinetti C and Lassmann H: Remyelination is extensive in a subset of multiple sclerosis patients. Brain 129: 3165-3172, 2006

3. Cohen JA, Barkhof F, Comi G, Hartung HP, Khatri BO, Montalban X, Pelletier J, Capra R, Gallo P, Izquierdo G, et al: Oral fingolimod or intramuscular interferon for relapsing multiple sclerosis. N Engl J Med 362: 402-415, 2010.

4. Kappos L, Radue EW, O'Connor P, Polman C, Hohlfeld R, Calabresi P, Selmaj K, Agoropoulou C, Leyk M, Zhang-Auberson L, Burtin P; FREEDOMS Study Group: A placebo-controlled trial of oral fingolimod in relapsing multiple sclerosis. N Engl J Med 362: 387-401, 2010.

5. Oo ML, Thangada S, Wu MT, Liu CH, Macdonald TL, Lynch KR, Lin CY and Hla T: Immunosuppressive and anti-angiogenic sphingosine 1-phosphate receptor-1 agonists induce ubiquitinylation and proteasomal degradation of the receptor. J Biol Chem 282: 9082-9089, 2007.

6. Mandala S, Hajdu R, Bergstrom J, Quackenbush E, Xie J, Milligan J, Thornton R, Shei GJ, Card D, Keohane C, et al Alteration of lymphocyte trafficking by sphingosine-1-phosphate receptor agonists. Science 296: 346-349, 2002.

7. Matloubian M, Lo CG, Cinamon G, Lesneski MJ, Xu Y, Brinkmann V, Allende ML, Proia RL and Cyster JG: Lymphocyte egress from thymus and peripheral lymphoid organs is dependent on S1P receptor 1. Nature 427: 355-360, 2004.

8. Chun J, Weiner JA, Fukushima N, Contos JJ, Zhang G, Kimura Y, Dubin A, Ishii I, Hecht JH, Akita C, et al: Neurobiology of receptor-mediated lysophospholipid signaling. From the first lysophospholipid receptor to roles in nervous system function and development. Ann NY Acad Sci 905: 110-117, 2000.

9. Rao TS, Lariosa-Willingham KD, Lin FF, Palfreyman EL, $\mathrm{Yu}$ N, Chun J and Webb M: Pharmacological characterization of lysophospholipid receptor signal transduction pathways in rat cerebrocortical astrocytes. Brain Res 990: 182-194, 2003.

10. Spiegel S and Milstien S: Sphingosine-1-phosphate: An enigmatic signalling lipid. Nat Rev Mol Cell Biol 4: 397-407, 2003.

11. Foster CA, Howard LM, Schweitzer A, Persohn E, Hiestand PC, Balatoni B, Reuschel R, Beerli C, Schwartz M and Billich A: Brain penetration of the oral immunomodulatory drug FTY720 and its phosphorylation in the central nervous system during experimental autoimmune encephalomyelitis: Consequences for mode of action in multiple sclerosis. J Pharmacol Exp Ther 323: 469-475, 2007

12. Choi JW, Gardell SE, Herr DR, Rivera R, Lee CW, Noguchi K, Teo ST, Yung YC, Lu M, Kennedy G, et al: FTY720 (fingolimod) efficacy in an animal model of multiple sclerosis requires astrocyte sphingosine 1-phosphate receptor 1 (S1P1) modulation. Proc Natl Acad Sci USA 108: 751-756, 2011.
13. Mullershausen F, Craveiro LM, Shin Y, Cortes-Cros M, Bassilana F, Osinde M, Wishart WL, Guerini D, Thallmair M, Schwab ME, et al: Phosphorylated FTY720 promotes astrocyte migration through sphingosine-1-phosphate receptors. J Neurochem 102: 1151-1161, 2007.

14. Osinde M, Mullershausen F and Dev KK: Phosphorylated FTY720 stimulates ERK phosphorylation in astrocytes via S1P receptors. Neuropharmacology 52: 1210-1218, 2007.

15. Sun H, Bénardais K, Stanslowsky N, Thau-Habermann N, Hensel N, Huang D, Claus P, Dengler R, Stangel M and Petri S: Therapeutic potential of mesenchymal stromal cells and MSC conditioned medium in Amyotrophic Lateral Sclerosis (ALS) - in vitro evidence from primary motor neuron cultures, NSC-34 cells, astrocytes and microglia. PLoS One 8: e72926, 2013.

16. Nicklas W, Baneux P, Boot R, Decelle T, Deeny AA, Fumanelli M and Illgen-Wilcke B; FELASA (Federation of European Laboratory Animal Science Associations Working Group on Health Monitoring of Rodent and Rabbit Colonies): Recommendations for the health monitoring of rodent and rabbit colonies in breeding and experimental units. Lab Anim 36: 20-42, 2002.

17. Pébay A, Toutant M, Prémont J, Calvo CF, Venance L, Cordier J, Glowinski J and Tencé M: Sphingosine-1-phosphate induces proliferation of astrocytes: Regulation by intracellular signalling cascades. Eur J Neurosci 13: 2067-2076, 2001.

18. Yoshida Y, Nakada M, Sugimoto N, Harada T, Hayashi Y, Kita D, Uchiyama N, Hayashi Y, Yachie A, Takuwa Y, et al: Sphingosine-1-phosphate receptor type 1 regulates glioma cell proliferation and correlates with patient survival. Int J Cancer 126: 2341-2352, 2010.

19. Sheridan GK and Dev KK: S1P1 receptor subtype inhibits demyelination and regulates chemokine release in cerebellar slice cultures. Glia 60: 382-392, 2012.

20. Van Doorn R, Van Horssen J, Verzijl D, Witte M, Ronken E, Van Het Hof B, Lakeman K, Dijkstra CD, Van Der Valk P, Reijerkerk A, et al: Sphingosine 1-phosphate receptor 1 and 3 are upregulated in multiple sclerosis lesions. Glia 58: 1465-1476, 2010.

21. Wu C, Leong SY, Moore CS, Cui QL, Gris P, Bernier LP, Johnson TA, Séguéla P, Kennedy TE, Bar-Or A, et al: Dual effects of daily FTY720 on human astrocytes in vitro: Relevance for neuroinflammation. J Neuroinflammation 10: 41, 2013.

22. Yamagata K, Tagami M, Torii Y, Takenaga F, Tsumagari S, Itoh S, Yamori Y and Nara Y: Sphingosine 1-phosphate induces the production of glial cell line-derived neurotrophic factor and cellular proliferation in astrocytes. Glia 41: 199-206, 2003.

23. Bauer J, Berkenbosch F, Van Dam AM and Dijkstra CD: Demonstration of interleukin-1 beta in Lewis rat brain during experimental allergic encephalomyelitis by immunocytochemistry at the light and ultrastructural level. J Neuroimmunol 48: 13-21, 1993.

24. Merrill JE: Tumor necrosis factor alpha, interleukin 1 and related cytokines in brain development: Normal and pathological. Dev Neurosci 14: 1-10, 1992.

25. Herx LM, Rivest S and Yong VW: Central nervous system-initiated inflammation and neurotrophism in trauma: IL-1 beta is required for the production of ciliary neurotrophic factor. J Immunol 165: 2232-2239, 2000.

26. Mason JL, Suzuki K, Chaplin DD and Matsushima GK: Interleukin-1beta promotes repair of the CNS. J Neurosci 21: 7046-7052, 2001

27. Arenas E, Trupp M, Akerud P and Ibáñez CF: GDNF prevents degeneration and promotes the phenotype of brain noradrenergic neurons in vivo. Neuron 15: 1465-1473, 1995

28. Henderson CE, Phillips HS, Pollock RA, Davies AM, Lemeulle C, Armanini M, Simmons L, Moffet B, Vandlen RA, Simpson LC corrected to Simmons L, et al: GDNF: A potent survival factor for motoneurons present in peripheral nerve and muscle. Science 266: 1062-1064, 1994.

29. Lin LF, Doherty DH, Lile JD, Bektesh S and Collins F: GDNF: A glial cell line-derived neurotrophic factor for midbrain dopaminergic neurons. Science 260: 1130-1132, 1993. 